\title{
Lugar de mulher é no YouTube: o feminismo popular de influenciadoras digitais socialmente engajadas
}

\author{
Women's place is on YouTube: the popular feminism of socially engaged \\ digital influencers
}

\section{Simone Evangelista Cunha}

Bolsista do Programa Nacional de Pós-Doutorado (PNPD/CAPES) do Programa de Pós-Graduação em Comunicação da Universidade Federal Fluminense (UFF). Doutora e Mestre em Comunicação pela mesma instituição. Pesquisadora do Laboratório de Pesquisa em Culturas e Tecnologias da Comunicação (LabCult/UFF).

Submetido em 29 de Agosto de 2020 Aceito em 12 de Dezembro de 2020

\section{RESUMO}

$O$ artigo analisa a disseminação de debates sobre os feminismos em plataformas digitais a partir da atuação de influenciadoras digitais socialmente engajadas, que têm a produção de conteúdos sobre o tema como elementos centrais de sua presença on-line. À luz de debates sobre as reconfigurações da atuação política em ambientes digitais e disputas pela identidade feminista na cultura do consumo, discutimos as representações do feminismo em três canais no YouTube: Jout Jout Prazer, Nátaly Neri e Nunca te Pedi Nada. Os resultados apontam para a necessidade de repensar a noção de feminismo popular a partir de nuances mais diversas e complexas.

PALAVRAS-CHAVE: feminismo popular; ativismo digital; feminismo e consumo; influenciadores digitais; YouTube.

\section{ABSTRACT}

The article analyzes the dissemination of debates about feminisms on digital platforms through the work of socially engaged digital influencers, who have the production of content on the theme as central elements of their online presence. From debates about the reconfigurations of political performance in digital environments and disputes for feminist identity in consumer culture, we discussed representations of feminism on three channels on YouTube: Jout Prazer, Nátaly Neri, and Nunca te Pedi Nada. The results point to the need to rethink the notion of popular feminism based on more diverse and complex nuances.

\section{Dossiê Crise, Feminismo e Comunicação - https://revistaecopos.eco.ufrj.br/}


KEYWORDS: popular feminism; digital athleticism; feminism and consumption; digital influencers; Youtube.

\section{Introdução}

Embora a relação entre feminismos e plataformas digitais seja objeto de debate frequente nos últimos anos (KELLER, 2013; FERREIRA, 2015; REIS 2017), este trabalho analisa o fenômeno sob um viés ainda pouco explorado: o de influenciadoras digitais cuja produção é fortemente atravessada por códigos do entretenimento e, simultaneamente, por discussões ligadas ao feminismo e ao feminismo negro. Acompanhando a progressiva transformação dos feminismos em estilo de vida (HOOKS, 2018), trata-se de mulheres cujo envolvimento com tais debates não inviabiliza o diálogo com instâncias publicitárias, vide a participação em diversas ações patrocinadas, inclusive relacionadas a debates caros ao movimento.

A categoria "influenciador digital", grosso modo, nomeia a profissionalização de indivíduos que constroem comunidades em torno de si em plataformas digitais, utilizando sua capacidade de expressão para interferir em decisões sobre consumo e estilos de vida, além das conversações que povoam diferentes ambientes digitais. Para tanto, adotam estratégias de visibilidade e contato com a audiência específicas, que autoras como Marwick (2013) e Senft (2013) classificam como práticas de microcelebridade. A disseminação de informações sobre a intimidade é um elemento central de tais práticas, articulando laços afetivos com o público que posteriormente serão mercantilizados de diferentes maneiras, como a publicação de conteúdos patrocinados (KARWAFI, 2016).

Tal qual outros exemplos de aproximação entre instâncias mercadológicas e acionamentos do feminismo (AMARAL, 2019), a emergência de influenciadoras digitais feministas no cenário midiático hodierno leva a questionamentos sobre as atualizações, possibilidades e ambiguidades do ativismo feminista na 
contemporaneidade. A proposta deste trabalho é analisar representações do feminismo em vídeos de três youtubers que classificamos como influenciadoras digitais ativistas, mulheres cuja produção de conteúdo e o reconhecimento da presença on-line, como aparições em veículos de comunicação e campanhas publicitárias, são marcados pela defesa de pautas sociais - ainda que não se limitem a estas. Os canais de Júlia Tolezano (Jout Jout Prazer) ${ }^{1}$, Maíra Medeiros (Nunca te Pedi Nada) ${ }^{2}$ e Nátaly Neri (Nátaly Neri) ${ }^{3}$ se tornaram populares por sua mescla de debates sobre temas vinculados ao engajamento social, frequentemente associados a pautas sociais como os feminismos, e conteúdos mais voltados ao entretenimento, como relatos sobre eventos de sua intimidade ou dicas de consumo.

Para tanto, propomos dois conjuntos de debates que problematizam e atualizam tais atravessamentos à luz da teoria feminista. Em um primeiro momento, retomamos algumas perspectivas sobre a relação entre feminismo e consumo, com ênfase nos debates sobre a pertinência do pós-feminismo e do feminismo popular (BANET-WEISER, 2018a) como chaves interpretativas para fenômenos diversos nesta seara. Em seguida, discutimos as ressignificações do ativismo a partir das possibilidades de conexão por meio das plataformas digitais. Localizamos a popularização de debates feministas na rede como parte de um histórico de manifestações que não necessariamente condizem com definições tradicionais (e excludentes) de ativismo, configurando-se como possibilidades para a elaboração de formas de ativismo discursivo feminista (CLARK, 2016). A partir de tais discussões, apresentamos uma análise sobre a produção dos canais mencionados entre os anos de 2016 e $2018^{4}$.

A niteroiense Júlia Tolezano, de 29 anos, é formada em jornalismo e

1 Disponível em: https://www.youtube.com/user/joutjoutprazer. Último acesso: 16/08/2020.

2 Disponível em: https://www.youtube.com/channel/UCYWtYb0GcYrhDxOykcUpzJw. Último acesso: $16 / 08 / 2020$.

3 Disponível em: https://www.youtube.com/channel/UCjivwB8MrrGCMlIuoSdkrQg. Último acesso: $16 / 08 / 2020$.

4 Este artigo apresenta parte dos resultados de tese sobre o tema (EVANGELISTA CUNHA, 2019). 0 presente trabalho foi realizado com apoio da Coordenação de Aperfeiçoamento de Pessoal de Nível Superior - Brasil (CAPES).

Dossiê Crise, Feminismo e Comunicação - https://revistaecopos.eco.ufrij.br/

ISSN $2175-8689$ - v. 23, n. 3, 2020

DOI: 10.29146/eco-pos.v23i3.27599 
começou a produzir vídeos para o YouTube em 2014. Desde então, já foi tema de diversas reportagens que a classificam como "cronista de uma geração" (RODROL e FINCO, 2016, on-line) e "nova sensação do YouTube" com "pegada de comédia stand up" (PARENTES, 2015). Seu canal é conhecido por uma suposta ausência de roteiros, abordando assuntos diversos. Entretanto, obteve visibilidade pela publicação de vídeos nos quais fala sobre temas do universo feminino pouco discutidos, como relacionamentos abusivos, desconfortos durante o sexo, repressão da sexualidade e cultura do estupro. Apesar de uma pausa anunciada em dezembro de 2019, o canal ainda somava 2,4 milhões de inscritos até agosto de 2020.

Maíra Medeiros tem 35 anos e é formada em publicidade. Seu canal, "Nunca te pedi nada", existe desde 2015 e conta com 2,3 milhões de inscritos. A youtuber conquistou visibilidade após o lançamento de paródias de cunho feminista de grandes sucessos da música pop brasileira. Seu vídeo mais popular até a finalização do artigo, com 3,7 milhões de visualizações, era "Miga sua loca", paródia de "Essa mina é louca", da cantora Anitta, que alerta contra relacionamentos abusivos. A youtuber diz ter criado o canal após algumas gravações "sem compromisso" para abordar temas que a "Maíra pequena precisava ter escutado para que ela crescesse melhor", privilegiando discussões de cunho feminista (XAVIER, 2017, on-line). Além destes tópicos, Medeiros também é reconhecida por abordar temas vinculados à cultura pop.

Nátaly Neri, de 26 anos, é estudante de Ciências Sociais na Universidade Federal de São Paulo (Unifesp) e comanda um canal homônimo (anteriormente denominado "Afros e Afins"), que soma pouco mais de 720 mil inscritos, desde 20155. Tal qual Medeiros, explica que sua principal motivação para o canal "foi fazer com que pessoas ouçam o que eu não ouvi" (MÍDIA NINJA, 2017, on-line). Participante de coletivos feministas vinculados a movimentos negros, ela se

5 Dentre as influenciadoras digitais brasileiras com produção de conteúdos relacionados ao ativismo no YouTube analisadas em 2016, data do início da pesquisa para a tese da autora, Neri era a mulher negra com maior número de seguidores. A inclusão de seu canal na amostra selecionada possibilitou debates sobre temas como as redes de ativismo formadas no portal de vídeos e as diferenças nas condições de visibilidade de mulheres brancas e negras no YouTube, que fogem ao escopo do presente artigo.

\section{Dossiê Crise, Feminismo e Comunicação - https://revistaecopos.eco.ufri.br/}




\section{DOSSIÊ}

tornou conhecida sobretudo por vídeos nos quais debate temas relacionados à autoestima negra, luta antirracista e feminismo negro. Nátaly também aborda frequentemente temas vinculados a sustentabilidade e veganismo, além de seu namoro com Jonas Maria, um homem transexual, buscando desmistificar tabus em torno da relação.

\section{Disputas pela identidade feminista na cultura do consumo}

Embora alguns autores e reportagens mencionem um "renascimento" do feminismo na mídia mais recentemente (FULLER e DRISCOLL, 2015), pode-se considerar a visibilidade de discussões ligadas ao movimento como parte de um deslocamento em curso há pelo menos 30 anos. Segundo Sarah Banet-Weiser (2018b), a representação feminina começou a sofrer alterações importantes na mídia norte-americana e europeia a partir dos anos 1980. Se na década anterior as feministas eram caracterizadas majoritariamente como mulheres à beira de um ataque de nervos que odiavam os homens, posteriormente a mídia começa a dar espaço para mulheres valorizadas por sua coragem e seu papel como indivíduos capazes decidir os rumos de suas próprias vidas (BANET-WEISER, 2018b, p. 152153). Ainda sob jugo da Ditadura Militar, a mídia brasileira acompanhou a movimentação6, fortemente ancorada na vinculação entre novas identidades femininas e a escolha de bens de consumo.

A partir sobretudo de trabalhos vinculados aos Estudos Culturais que enfatizavam a capacidade de negociação e agenciamento de leitores, espectadores e consumidores (FISKE, 1989; ABERCROMBIE e LONGHURST, 1998), o consumo passou a ser ressignificado como espaço para a imaginação e movimentos de resistência por correntes até então dominadas por debates mais voltados a críticas sobre seu potencial alienante. Concomitantemente, setores do movimento feminista também discutem a possibilidade de emancipação feminina a partir

6 Dirigida por Daniel filho e protagonizada pela atriz Regina Duarte, a série Malu Mulher, exibida pela Rede Globo entre 1979 e 1980, tornou-se emblemática neste sentido (MEMÓRIA GLOBO, on-line).

Dossiê Crise, Feminismo e Comunicação - htttps://revistaecopos.eco.ufrj.br/ 


\section{DOSSIÊ}

dessa esfera. Como pontua Brunsdon, "usar batom não é mais repulsivo, e noções de identidade se distanciaram de um eixo racional/moral e são muito mais profundamente informadas por ideias de performance, estilo e desejo" (BRUNSDON, 1997, p.85 apud FREIRE FILHO, 2007, p, 120).

Ao longo dos anos 1990, o movimento de visibilidade de práticas e produtos associados ao "girl power" na mídia se intensificou a ponto de transformar a retórica da emancipação feminina em normativa, explica Sarah Banet-Weiser (2018b). Mais do que uma tendência, tratava-se de uma cultura emergente, identificada por autoras como Rosalind Gill (2007) e Angela McRobbie (2009) como pós-feminismo. Em síntese, embora tenha sido operacionalizado de formas diversas ao longo do tempo, o conceito está relacionado a "um conjunto de ideologias, estratégias e práticas em torno de discursos feministas liberais, como liberdade, escolha e independência incorporado em um contexto mais amplo de mídia, merchandising e participação do consumidor" (BANET-WEISER, 2018b, p. 153). Para a socióloga britânica Rosalind Gill (2007), o pós-feminismo pode ser traduzido como um tipo de sensibilidade que agrega temas interrelacionados, incluindo a ênfase na autodisciplina, monitoramento e vigilância de si, a valorização das escolhas individuais e empoderamento e a "transformação" (makeover) como um paradigma a ser seguido. Diferentemente do feminismo "ortodoxo" e sua crítica às condições estruturais da desigualdade entre os gêneros (KELAN, 2009), a sensibilidade pós-feminista é centrada na capacidade de ação no corpo feminino, tido como "espaço de liberação" (BANET-WEISER, 2018b, p. 153). Representa, para seus críticos, o recrudescimento do ativismo político e uma rejeição ao feminismo (MCROBBIE, 2009) - ou, como aponta Gill, uma forma, às vezes contraditória, de articular discursos antifeministas e feministas, resultando em construções de gênero que apresentam as mulheres como sujeitos ativos, desejantes e empoderados e, simultaneamente, reinscrevem os corpos femininos como objetos sexuais (GILL, 2007).

Segundo McRobbie, o prefixo "pós" sugere que o pós-feminismo pode ser entendido como uma tentativa de substituir ou deslocar o feminismo como

\section{Dossiê Crise, Feminismo e Comunicação - https://revistaecopos.eco.ufrj.br/}




\section{DOSSIÊ}

movimento político. Ao oferecer uma forma de engajamento com noções de empoderamento feminino que dispensam o feminismo - vale ressaltar, reconhecendo sua relevância histórica, mas apontando que sua agenda política estaria "superada" - o pós-feminismo recompensaria suas adeptas com o que a autora denomina de "novo contrato sexual" (MCROBBIE, 2009, p.57). Abandonarse-ia a crítica ao patriarcado em troca de visibilidade no mercado de trabalho e na cultura do consumo, possibilitadas pela adoção de uma série de práticas conjuntamente "progressistas" e "tranquilizadoramente femininas" (idem).

Para Freire Filho (2007), o pós-feminismo representaria, simultaneamente, uma forma de se apropriar e distorcer as bases das discussões propostas pela "segunda onda" feminista, considerada "desesperançada e repressora, interessada em submeter as mulheres a um conjunto limitado de comportamentos e crenças 'politicamente corretas', em que todos os aspectos da vida pessoal são rigidamente prescritos e policiados" (2007, p. 142). Em texto publicado em 2004, Jennifer Baumgardner e Amy Richards seguem nesta direção na defesa de um feminismo "feminino" (girlie) como alternativa para o engajamento das mulheres mais jovens em contraponto à associação entre feminilidade e subordinação masculina. Diferentemente das gerações mais antigas, parte das novas feministas não encararia a rejeição ao consumismo como uma pré-condição para salvaguardar sua atuação política (BAUMGARDNER e RICHARDS, 2004).

Tal posicionamento à primeira vista, soa como uma confirmação dos debates sobre a preponderância da sensibilidade pós-feminista na contemporaneidade. Afinal, para autoras como McRobbie e Duggan, o pósfeminismo deve ser compreendido no contexto do neoliberalismo, no qual o consumidor-cidadão é continuamente incentivado através de termos "neutros" como "responsabilidade individual", "escolha" e "empoderamento" a melhorar a si mesmo, encontrar oportunidades e soluções individuais para obstáculos estruturais (DUGGAN, 2012). Em crítica contundente, McRobbie argumenta que, ao desencorajar a identificação com o feminismo radical, o pós-feminismo não apenas mitigaria novas formas de ativismo que poderiam surgir, mas reinstalaria novas

\section{Dossiê Crise, Feminismo e Comunicação - https://revistaecopos.eco.ufrj.br/}




\section{DOSSIÊ}

hierarquias de gênero, retroalimentando o poder patriarcal (MCROBBIE, 2009, p. 47). Desta forma, os discursos de empoderamento do pós-feminismo teriam efeito diametralmente oposto à sua proposta, esvaziando a possibilidade de transformação efetiva na desigualdade de gêneros. Em termos práticos, o efeito do pós-feminismo seria desfazer o feminismo (idem).

Não obstante, para além da popularização de bens consumo com mensagens de "empoderamento" feminino, o florescimento de diversas manifestações ativistas de cunho feminista em diferentes países e a presença constante de debates relacionados ao feminismo na mídia nos últimos anos parecem desmentir a previsão sombria de McRobbie. Seria natural, portanto, questionar se o termo pósfeminismo estaria ultrapassado como lente teórico-metodológica para compreender as intercessões entre a cultura midiática e o feminismo nos dias correntes, o que foi feito por autoras como Catharine Lumby (2011) e Imelda Whelehan (2010). Para Keller e Ryan (2014), por exemplo, a insistência em utilizar o termo demonstraria o apego a uma retórica sobre as ameaças ao feminismo que não refletiria sua visibilidade na mídia internacional. Segundo as autoras, as discussões sobre gênero na mídia têm aparecido de forma integrada a demandas feministas, como o fim da cultura do estupro ou a ausência de personagens femininas fortes nos filmes. Diante de uma nova realidade, portanto, caberia à teoria feminista buscar outras referências para compreender o panorama e as perspectivas do movimento.

Em resposta às críticas ao pós-feminismo, Rosalind Gill apresenta uma visão mais matizada do conceito para defender a permanência de sua relevância. Em releituras do pós-feminismo publicadas em 2016 e 2017, a autora admite que o feminismo adquiriu uma visibilidade que não tinha quando o termo começou a ser discutido - nos países ocidentais, pontua, a maior parte dos debates está mais presente na mídia do que fora dela. Contudo, mais do que um indicativo de que a mídia finalmente estaria se tornando feminista, essa ascensão, em sua opinião, "é parte de um processo cíclico - e às vezes cínico" (GILL, 2016, p. 615). Para cada iniciativa ativista feminista, lembra Gill, surge outra relacionada à misoginia; cada

Dossiê Crise, Feminismo e Comunicação - https://revistaecopos.eco.ufri.br/ 
"vitória" feminista é seguida por ondas de ódio e ameaças, cada manifestação de solidariedade compete com trollagens que buscam desestabilizar o movimento (idem, p. 613). Segundo a autora, é necessário fazer uma distinção entre o que pode ser classificado como feminismo corporativo/neoliberal e "o feminismo ativista daquelas que estão protestando contra cortes de verba de serviços para as mulheres ou contra a deportação de imigrantes" (GILL, 2016, p. 612).

Em diálogo com a autora, Banet-Weiser qualifica o feminismo em circulação na mídia comercial como "feminismo popular" (2018a, p. 154) e estabelece paralelos entre este e a noção de pós-feminismo. Embora se trate de manifestações diferentes, existem elementos em comum, pontua a autora. Enquanto o pósfeminismo invisibiliza o feminismo, o feminismo popular, segundo Banet-Weiser, constroi uma versão espetacularizada que, por isso mesmo, pode se tornar visível. Ao reconhecer a desigualdade de gêneros e a vulnerabilidade da mulher, o segundo oferece uma visão que problematiza algumas questões, "afastando-se do vago slogan 'girl power' do pós-feminismo" (idem). Entretanto, embora seja uma "correção necessária” ao otimismo do pós-feminismo, o feminismo pop apresenta medidas liberais como soluções para os problemas discutidos.

A partir destas colocações, concordamos com Gill (2016) quando a autora propõe um "uso crítico" do termo pós-feminismo na contemporaneidade - o que se aplicaria, por exemplo, ao seu uso para análises de certos elementos que compõem o feminismo pop. Apostamos que se trata de um conceito potencialmente produtivo para pensar nas múltiplas formas pelas quais valores relacionados ao feminismo são apropriados, selecionados e envolvidos em diferentes contextos de formas complexas. Conforme Gill argumenta, tal qual o aumento de iniciativas ativistas anticapitalistas "não deve nos levar à falsa crença de que o capitalismo não existe mais, o aumento do ativismo feminista não significa que ideias préfeministas, anti-feministas e pós-feministas não estejam mais em circulação" (GILL, 2016, p. 622). Essas ideias, em diversas ocasiões, não apenas coexistem em um mesmo momento e espaço, mas aparecem combinadas de formas contraditórias e inesperadas.

Dossiê Crise, Feminismo e Comunicação - https://revistaecopos.eco.ufrj.br/ 
Neste sentido, trabalharemos com as noções de feminismo popular e pósfeminismo não necessariamente para pensar uma mídia pós-feminista, como sugere Gill, mas para construir uma reflexão crítica sobre produtos midiáticos populares que podem evocar a sensibilidade pós-feminista em alguns momentos e, em outros, acionar debates mais próximos ao feminismo "tradicional" ou "ortodoxo". Entender essa complexidade passa, inclusive, por analisar as representações do feminismo com um olhar que recuse a simples dualidade entre o que seria o ativismo "legítimo" e uma apropriação "sem conteúdo", armadilha recorrente nos debates sobre a relação entre feminismo, mídia e consumo.

\section{Cidadania cultural e atuação política na cultura do quarto}

Em tese sobre blogueiras adolescentes feministas, Jeosallyn Keller (2013) argumenta que o próprio conceito "tradicional" de ativismo é historicamente pautado por processos de exclusão, privilegiando a experiência de homens brancos de classe média (KELLER, 2013). Relacionada a ações para a melhora de determinados aspectos da sociedade através de estratégias de intervenção política (KLAR e KASSER, 2009), a noção predominante de ativismo não dialoga, segundo Keller, com indivíduos cujo poder de agência é constantemente negado ou questionado, como as jovens blogueiras que analisa. Por isso, concepções mais amplas de ativismo são fundamentais para compreender melhor como mulheres, sobretudo negras, jovens, pobres e não-ocidentais, têm se engajado politicamente (TAFT, 2011). Neste sentido, Keller dialoga com a noção de cidadania cultural, relacionada às práticas culturais que permitem participação social. Atividades cotidianas, cultura popular e plataformas digitais são destacadas por diferentes pesquisas como instâncias relevantes para tais práticas, sobretudo por sua atuação nos processos de elaboração de identidades individuais e coletivas (BURGESS, FOTH E KLAEBE, 2006). Um "modelo feminista de cidadania cultural", portanto, incluiria a percepção de que as mulheres podem agir de formas múltiplas, 


\section{DOSSIÊ}

transitando entre as esferas do público e do privado (KELLER, 2013, p. 312) e participando muitas vezes de "políticas informais" (LISTER, 1997).

Nesta direção, cabe retomar o conceito de ativismo discursivo feminista (YOUNG, 1997) como uma possível chave interpretativa para formas de mobilização feminista a partir da mídia. Trata-se da construção, por meio do discurso, de articulações que dão visibilidade a estruturas de poder hegemônicas presentes na vida cotidiana (idem). Articulando esse debate ao nosso objeto, a ideia de cotidianidade pode ser acionada tanto a partir do compartilhamento de relatos singelos, muitas vezes banais, sobre a vida das youtubers analisadas, quanto pelo próprio hábito de acompanhar suas rotinas por meio de plataformas digitais, que vão construir uma relação de intimidade entre criadores e suas audiências.

Além de uma noção excludente de ativismo, outro fator que dificulta a análise de determinados fenômenos contemporâneos está em binarismos entre cultura e política que abrangem parte da literatura sobre manifestações ativistas digitais de forma mais ampla, conforme pontua Rosemary Clark (2016). A autora argumenta que o discurso mediado digitalmente quase sempre é visto como "um recurso cultural mobilizado para ações políticas offline" (CLARK, 2016, p. 794), ou seja, a partir de uma negação de seu caráter político per se. 0 debate sobre "efetividade" de manifestações restritas à esfera digital, crescente nos últimos anos (PAPACHARISSI, 2015; HIGHFIELD, 2016, TUFECKI, 2012), foge às discussões propostas neste artigo. Entretanto, ressaltamos que partir do pressuposto de que a pluralização de debates mediados por plataformas digitais só ganha legitimidade ao sair das redes é ignorar a própria centralidade de tais espaços na vida cotidiana de uma parte cada vez maior da população global (HINE, 2015).

Em diálogo com Young (1997), Shaw (2012) defende que o discurso on-line pode ser considerado uma forma de ativismo capaz de provocar transformações sociopolíticas com ou sem o apoio de ações "offline". Ao definir tal atuação enquanto ativismo discursivo, Young vai ao encontro de debates sobre o ativismo linguístico feminista, compreendido por autores como Anne Pauwels (2003) como

Dossiê Crise, Feminismo e Comunicação - https://revistaecopos.eco.ufrj.br/

ISSN 2175-8689 - v. 23, n. 3, 2020

DOI: 10.29146/eco-pos.v23i3.27599 


\section{DOSSIÊ}

um ativismo que parte do princípio de que a linguagem e a sociedade constroem-se mutuamente e, assim, propõe alternativas a formas de linguagem sexistas. Nesta direção, formas de mobilização on-line que buscam produzir "novos vocabulários, novos paradigmas através dos quais indivíduos, coletividades e instituições interpretam circunstâncias sociais e produzem respostas a elas" (YOUNG, 1997, p. 3) podem ser consideradas como formas de ativismo discursivo feminista.

Trata-se de manifestações que ecoam o caráter descentralizado de mobilizações sociais hodiernas e que, no âmbito do feminismo, demandam um entendimento mais fluido do movimento e a utilização de termos como "fazer feminismo cotidiano" (NAPLES, 2005) ou "feminismo em construção" (doing feminism) (PIEPMEIER, 2009). No dia-a-dia, e em relações estabelecidas a partir da produção midiática de caráter feminista, jovens e mulheres passam a se reconhecer em identidades feministas (KELLER, 2013). Refletem, assim, a "desordem" (HEYWOOD e DRAKE, 1997) do feminismo contemporâneo, pautado pelos atravessamentos entre políticas de coalizão sempre em movimento, identidades multifacetadas e práticas divertidas de resistência e ativismo (KELLER, 2013). De dentro de seus quartos, jovens mulheres que produziam zines e outras mídias alternativas com tesoura e cola na década de 1990 hoje utilizam seus laptops para a criação de fanfics e blogs, reinventando o próprio feminismo neste processo (MARWICK, 2017).

Evidentemente, nem toda mídia produzida por mulheres será necessariamente classificada de acordo com noções mais tradicionais do feminismo, abordando "a politização da cultura em resistência à opressão patriarcal" (VEBER e MITCHELL, 1998, p. 75) ou mesmo desafiando desigualdades relacionadas aos gêneros, raças e classes sociais (KELLER, 2013). Entretanto, dentre aquelas que apresentam algum reconhecimento pela realização de debates feministas, há diferenças consideráveis, por exemplo, entre jovens que se dedicam a organizar campanhas ou publicações feministas sem fins lucrativos e movimentos como a emergência de influenciadoras digitais ativistas ligadas ao tema. Além da vinculação com instâncias mercadológicas, as lógicas de visibilidade

\section{Dossiê Crise, Feminismo e Comunicação - https://revistaecopos.eco.ufrj.br/}




\section{DOSSIÊ}

características de plataformas digitais são apontadas como questões problemáticas para a análise de discursos individuais femininos nestes ambientes.

Para Banet-Weiser (2011), por exemplo, as identidades femininas construídas no YouTube obedecem a roteiros alinhados a um "contexto cultural e econômico de imagens, textos, crenças e valores reconhecíveis e prédeterminados" (BANET-WEISER, 2011, p. 284). Neste cenário, as narrativas femininas se apresentariam de acordo com imagens moldadas pela cultura popular: articulando ideias de autonomia e liberdade de escolha dentro de uma lógica individualista, marcada pelo empreendedorismo de si (GENZ, 2015) e por padrões corporais e de conduta (BANET-WEISER, 2011, p. 284). A autora sugere que as identidades de gêneros são "ativamente re-imaginadas" (2012, p. 21) em espaços on-line fora do Youtube, defendendo a necessidade de estabelecer uma comparação entre estes espaços e a plataforma a fim de questionar o caráter normativo do processo de elaboração de marcas pessoais (self-brand) na rede. Aproximando o debate da análise aqui proposta, tal pressuposto considera que as dinâmicas de visibilidade dominantes em plataformas como o YouTube reiteram sensibilidades pós-feministas, inviabilizando formas de ativismo feminista. Não obstante a pertinência da relação entre pós-feminismo, neoliberalismo e as lógicas que atravessam a relevância em plataformas digitais, argumentamos que tal caracterização tende a invisibilizar arenas importantes para discussões sobre o feminismo, conforme investigaremos a seguir.

\section{Procedimentos metodológicos}

Para selecionar a amostra a ser analisada, todas as produções publicadas entre os anos de 2016 e 2018 nos canais "Nunca te Pedi Nada", "Nátaly Neri" e "Jout Jout Prazer" foram avaliadas, somando 871 vídeos. Este primeiro levantamento buscou identificar produções diretamente relacionadas aos seguintes temas: feminismo, empoderamento feminino, ativismo, militância e política. Para tanto, foram mapeados o título, a descrição e, quando estes não possibilitavam a

\section{Dossiê Crise, Feminismo e Comunicação - https://revistaecopos.eco.ufrj.br/}


identificação do vídeo, os primeiros minutos de cada produção. Diante de uma quantidade expressiva de vídeos sobre causas sociais diversas, como luta contra o racismo, populações LGBTQ+ e defesa do meio ambiente, buscamos nos ater àqueles que mencionassem mais explicitamente discussões ligadas ao bem-estar feminino e/ou ao ativismo de forma mais ampla.

A investigação do material se baseou principalmente com a análise de conteúdo (BARDIN, 2010). A partir de uma leitura intensa dos dados (GIBBS, 2009), realizamos a codificação do material coletado, que consiste em identificar passagens relacionadas a determinados temas (idem) para construir categorias analíticas relevantes à compreensão do fenômeno estudado. De modo a promover o equilíbrio entre diferentes vídeos analisados, elaboramos a seguinte tipologia inicial, compreendendo que tais categorias, por vezes, se sobrepõem em uma mesma produção: vlogs, opiniões, colaborações e vídeos comerciais. Em relação à categoria vlog, procuramos nos ater ao discurso das próprias youtubers para estabelecer uma classificação. Estes vídeos apresentam algum elemento da rotina ou vivência das youtubers em "tempo real". Já os vídeos classificados como opinião são aqueles nos quais elas oferecem seu ponto de vista em uma espécie de ensaio sobre determinados assuntos. As colaborações são vídeos nos quais entrevistam ou conversam com outras mulhereres, enquanto vídeos comerciais são aqueles diretamente vinculados a empresas. Embora intercambiáveis, tais categorias foram úteis para elaborar questões discutidas posteriormente, como as diferenças de performance em vídeos de opinião "independentes" e em vídeos comerciais. A partir de uma nova etapa de codificação, foi construída uma classificação integrando elementos de caráter mais descritivo e analítico que seriam utilizados para codificar o material.

Neste artigo, apresentamos os resultados relativos a duas categorias: 1) feminismo/empoderamento feminino, no qual especificamos de que forma o vídeo se relaciona com essas temáticas específicas; e 2) menção a outras lutas identitárias e/ou à política de forma mais ampla, campo que identifica possíveis articulações entre os feminismos e outras formas de ativismo, bem como maneiras

\section{Dossiê Crise, Feminismo e Comunicação - https://revistaecopos.eco.ufrij.br/}


pelas quais as youtubers buscavam se posicionar enquanto mulheres socialmente engajadas. Após a definição da codificação, foi realizada uma nova classificação entre os vídeos para reduzir a amostra inicial a 60 vídeos, 20 de cada youtuber. Além do equilíbrio de produções de acordo com a tipologia inicial (vlogs, opiniões, colaborações e vídeos comerciais) para cada uma das youtubers, a seleção utilizou como critérios o ano de criação dos vídeos e, finalmente, o número de visualizações dos mesmos.

\section{Discursos sobre feminismo e articulações coletivas do movimento}

Considerando a lógica comercial em torno da popularização das youtubers em questão, uma hipótese da pesquisa dizia respeito a uma possível substituição de debates relacionados ao feminismo em prol de um vago conceito de empoderamento, termo relativamente banalizado pelo acionamento indiscriminado em campanhas publicitárias e representações diversas7 ${ }^{7}$ Entretanto, a análise do material coletado traz constatações que vão na direção contrária a essa proposição. 0 termo empoderamento (ou similares, como girl power) aparece em poucas ocasiões. Entre as exceções encontradas, estão dois vídeos de Maíra Medeiros. Em um deles, a jovem utiliza o termo ao descrever a atitude de uma modelo em um episódio de assédio: "Eu acho que o mundo precisa realmente de muito mais girl power"8, afirma. Em outro vídeo, parte de uma campanha publicitária para a marca Cravo \& Canela, mostra orgulho pela parceria com uma "marca muito girl power". Quando o mencionam, as youtubers deixam claro na maior parte das vezes que não se trata de um sinônimo para o feminismo.

7 Para debate sobre a relação entre empoderamento, visibilidade e exposição da intimidade no YouTube a partir de representações femininas não relacionadas aos feminismos, ver LANA (2017).

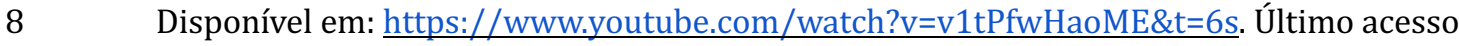
em: 10 ago. 2020.

9 Disponível em: https://youtu.be/dXh6_cM2qlU. Último acesso em: 10 ago. 2020.

Dossiê Crise, Feminismo e Comunicação - https://revistaecopos.eco.ufrj.br/

ISSN 2175-8689 - v. 23, n. 3, 2020

DOI: 10.29146/eco-pos.v23i3.27599 
Em um vídeo no qual analisa casos de machismo durante o ano de 2016 Maíra explica que o empoderamento feminino ganhou destaque na mídia e nos discursos publicitários daquele período, o que deu visibilidade a discussões sobre o feminismo. Na mesma produção, ela reitera a necessidade de "se manifestar e passar essa ideia de empoderamento feminino $e$ de feminismo". Nos minutos finais, diz ainda que "em 2017 a gente tem que continuar muito com empoderamento feminino e também com muito feminismo". Nesta e em outras menções da youtuber e de Júlia Tolezano ao termo, a ideia de empoderamento refere-se, basicamente, a aprendizados acumulados por cada mulher.

A correlação entre a noção midiatizada de empoderamento e um processo de fortalecimento individual se torna mais explícita em vídeos de Nátaly Neri. Em uma produção de 2018 em que apresenta uma espécie de "balanço" de seu canal11, a youtuber recupera imagens publicadas em 2015, nas quais afirmava que "o empoderamento acontece de forma individual? Acontece. Acontece quando você toma consciência de você mesmo e da sua realidade enquanto indivíduo, no mundo", pontua, para em seguida enfatizar a relevância da dimensão coletiva do termo. "Empoderamento não é só autoestima e amor próprio (...) É você ter consciência política do porquê você se ama", explica. Em um vídeo de 2016, denominado "Empoderamento vende!"12, a youtuber faz uma crítica mais direta à ênfase do discurso publicitário sobre noção de autoestima em detrimento da luta feminista: "as marcas tão falando sobre poder do feminismo, estão falando sobre girl power. Mas por que florear, por que não falar sobre feminismo? Girl power? 0 que é isso? A gente está falando de feminismo, um processo histórico, de luta", argumenta.

Ao analisarmos as falas das youtubers especificamente sobre feminismos, encontramos discursos que não apenas defendem o movimento feminista, mas

\footnotetext{
10 Disponível em: https://youtu.be/eQPYtPfxSX4. Último acesso em: 10 ago. 2020.

11 Disponível em: https://www.youtube.com/watch?v=X2abNOm WTA. Último acesso em: 10 ago. 2020.

12 Disponível em: https://www.youtube.com/watch?v=eqHFi8CHjH8. Último acesso em: 10 ago. 2020 .
}

Dossiê Crise, Feminismo e Comunicação - https://revistaecopos.eco.ufri.br/ 


\section{DOSSIÊ}

reforçam sua relevância dentro de um processo histórico, como faz Nátaly Neri. Curiosamente, embora utilize menos o termo, a youtuber dialoga frequentemente com reivindicações "tradicionais" do movimento, localizando a cultura patriarcal enquanto parte de um sistema de opressão feminina que sustenta estruturas sociais vigentes. Em um vídeo sobre o Dia da Mulher13, critica o clima festivo em torno da data: "Não é para se comemorar, é para a gente lembrar (...). É um dia de luta, é um dia de resistência, é um dia de pausa, principalmente para você olhar ao seu redor e entender que forças atuam contra você". Em outra produção, na qual debate a relação entre assédio e mobilidade urbana ${ }^{14}$, apresenta mais informações sobre o que seriam essas forças. Ao explicar o histórico de confinamento da mulher branca ao espaço privado e de opressão da mulher negra nos espaços públicos, a jovem explicita que esse movimento "não fala para a gente que a mulheres tem um dom natural de cuidar da casa, dos filhos e do marido, fala para a gente do patriarcado, fala a gente do capitalismo, da divisão sexual do trabalho".

A dona do canal "Nunca te pedi nada" foi a youtuber que mais mencionou o termo feminismo diretamente nos vídeos analisados. No vídeo sobre machismo em 2016, Maíra Medeiros diz que é uma "vergonha” as mulheres ainda precisarem fazer reivindicações relacionadas à igualdade de direitos. "É vergonhoso falar que as mulheres precisam disso em 2016? É, mas é a nossa realidade, cara. Por mais que a gente tivesse tido inúmeras conquistas no passado a gente precisa de muitas outras", explica. Em outro vídeo15, o feminismo é apresentado como "um movimento que defende a igualdade de direitos entre os homens e as mulheres. É muito simples e não é nada parecido com o que um monte de gente acha", define. Em diferentes momentos, a youtuber também parece privilegiar a relação entre feminismo e liberdade: "eu sou feminista porque eu quero ter liberdade de ser empresária e quero que a minha amiga tenha liberdade de ser dona de casa se ela

13 Disponível em: https://www.youtube.com/watch?v=XRK91MP5QZQ. Último acesso em: 10 ago. 2020.

14 Disponível em: https://www.youtube.com/watch?v=agNVQqkmTiE. Último acesso em: 10 ago. 2020.

15 Disponível em: https://www.youtube.com/watch?v=2VFwUI5n4eg. Último acesso em: 10 ago. 2020 .

Dossiê Crise, Feminismo e Comunicação - htttps://revistaecopos.eco.ufrj.br/

ISSN 2175-8689 - v. 23, n. 3, 2020

DOI: 10.29146/eco-pos.v23i3.27599 
quiser". Conforme debatido anteriormente, trata-se de um discurso bastante alinhado às demandas neoliberais que enfatizam o bem-estar e a liberdade femininas, promovidos sem um sem-número de produtos e serviços à disposição (anunciados antes, durante e depois de vídeos como esses no YouTube). Neste sentido, pode-se pensar que os discursos de Maíra Medeiros exemplificam construções nas quais coexistem valores associados à sensibilidade pós-feminista (GILL, 2016) e também a formas mais flexíveis de ativismo feminista. Ao fim desta e de outras produções no período, Maíra pede para que o público siga "fazendo barulho" para questionar desigualdades, em uma dinâmica que, por um lado, favorece o engajamento do público junto ao seu canal, mas também vai além da esfera individual ou de uma simples captura de valores feministas em prol do consumo.

Assim como Maíra e Nátaly, Júlia Tolezano também se apresenta em diversos momentos como uma espécie de porta-voz do feminismo para o público leigo. Essa característica é particularmente explicitada em um vídeo patrocinado no qual a jovem é encarregada de debater algumas questões sobre o movimento. Logo no início, ela anuncia que seu objetivo não é oferecer respostas aprofundadas, mas apenas responder a "perguntas básicas para quem está querendo entender agora rapidinho uns conceitos básicos de feminismo". Para ela, o feminismo é muito "você agir em cima do que você acredita que é o correto para a sociedade"16.

Neste e em outros vídeos da amostra selecionada, debates envolvendo estruturas de poder organizadas em torno do machismo, bem como discussões sobre a relação entre dominação patriarcal e capitalismo são praticamente ignorados pela youtuber. Júlia mostra uma postura no mínimo otimista (ou ingênua, a depender da interpretação) ao afirmar que "se você for olhar bem pro feminismo, ele é top. As pessoas que ficam muito contra o feminismo, elas só não leram sobre, não entenderam, alguém não foi lá e explicou". Entretanto, em um

16 Disponível em: https://www.youtube.com/watch?v=2N71eKQRqFs. Último acesso em: 10 ago. 2020.

Dossiê Crise, Feminismo e Comunicação - https://revistaecopos.eco.ufri.br/ 
vídeo sobre o conceito de sororidade ${ }^{17}$, Júlia critica a cultura da competição entre as mulheres, explicando que "Isso é muito cagado porque a gente precisa dessa parceria realmente pra conseguir seguir bem".

Sua estratégia, em certos sentidos, é menos didática no sentido de contextualizar as afirmações, sobretudo historicamente, procurando enfatizar os impactos de determinadas ações no seu próprio cotidiano e no de quem assiste. "Apesar das coisas que aconteceram, a gente poderia estar se juntando e se ajudando a seguir bem", reclama. Embora não mencione abertamente articulações políticas coletivas, defende uma união entre as mulheres: "É muito mais real e justo e consciente você se considerar parte de um grupo de pessoas incríveis". Entretanto, articulações coletivas provenientes dessa identificação parecem ficar em segundo plano.

\section{1 Explicando os feminismos}

Além de defender a necessidade de debates sobre o feminismo e o feminismo negro de modo mais amplo, os canais analisados buscam esclarecer nomenclaturas e debates emergentes sobre esses temas nas plataformas digitais. No material analisado, constatamos reivindicações frequentes das youtubers por um lugar de mediação entre discussões que estão acontecendo na esfera da "militância" e o público mais amplo.

Nátaly Neri afirma em diferentes vídeos que espera contribuir para a educação do público por compartilhar seus conhecimentos, sobretudo em um contexto de excesso de informações em circulação. A youtuber se diferencia das demais por apresentar referências bibliográficas acadêmicas e dados demográficos para embasar parte das discussões apresentadas. Já Maíra Medeiros e Júlia Tolezano possuem vídeos nos quais abordam especificamente termos do léxico feminista que ganharam destaque no período analisado. Termos em inglês de difícil

17 Disponível em: https://www.youtube.com/watch?v=f 445hsikNE. Último acesso em: 10 ago. 2020.

Dossiê Crise, Feminismo e Comunicação - https://revistaecopos.eco.ufrj.br/ 
tradução como gaslighting ("quando um cara começa a te fazer acreditar que você é louca") ou mansplanning são dissecados no canal de Maíra. A tentativa de aproximação com a realidade do público é apresentada em títulos como "Analisando as piores explicações dos homens (mansplaining)"18. Tais produções são baseadas sobretudo na interpretação da youtuber para as terminologias, sem definições formais.

Da mesma forma, o vídeo "Comentando mimimi demacho chorão (male tears)"19 apresenta Maíra lendo comentários que exemplificam as chamadas male tears (lágrimas masculinas). "Muitos caras não reconhecem que têm privilégios sociais. São pequenos privilégios que fazem com que eles vão mais à frente financeiramente, socialmente", explica, enumerando questões como salários mais altos e ausência de preocupações com assédio e estupro. "Eles não somente não entendem, mas eles choram. Essas são as male tears e normalmente são derramadas quando as mulheres falam alguma coisa". Em direção semelhante, além do supracitado vídeo sobre o conceito de sororidade, Júlia Tolezano explica as ideias de "interrompomem" e "explicomem", traduções dos termos manterrupting e mansplaning, na já mencionada produção em que debate conceitos básicos sobre o feminismo.

Uma vez que a compreensão sobre tais discussões pode contribuir para a inserção do público em debates feministas tanto nos próprios espaços de interação dos respectivos canais quanto em outras instâncias, consideramos o trabalho das youtubers como parte de um potencial processo de cidadania cultural a partir do feminismo (KELLER, 2013). Embora sejam expressões individuais, tais iniciativas podem fomentar ações coletivas diversas, além de disseminar "ideias facilmente personalizáveis" (CLARK, 2016, p. 790). Formas de interação a partir de um vídeo, tais quais o compartilhamento de relatos nos comentários ou o compartilhamento do próprio vídeo em outras plataformas de rede social, podem ser compreendidas a partir deste enquadramento de acordo com as mensagens ali difundidas e sua

18 Disponível em: https://youtu.be/LC1HNTzeE\&t=487s. Último acesso em: 10 ago. 2020.

19 Disponível em: https://youtu.be/Htl6WkItKxg. Último acesso em: 10 ago. 2020.

Dossiê Crise, Feminismo e Comunicação - https://revistaecopos.eco.ufrj.br/ 
ação conectiva (BENNETT e SEGERBERG, 2013), ou o poder de "produzir e conectar histórias individuais" (CLARK, 2016, p. 789) vinculadas a formas de ativismo feminista discursivo.

Tal potencial, bem como a valorização de demandas feministas pelos canais analisados, parece coexistir com outras articulações em torno dos movimentos. Considerando que o vínculo e o conhecimento sobre tais debates integram a marca pessoal das influenciadoras no ambiente do YouTube, podemos pensar no feminismo enquanto valor intangível que poderá objetivamente transformado em lucro, seja pela monetização de vídeos sobre o tema no YouTube (e pela audiência que são capazes de alcançar), seja por despertar o interesse de anunciantes interessados em demonstrar seu apoio às discussões. Neste sentido, faz-se oportuna uma leitura destes canais como uma continuação do que Banet-Weiser classifica como feminismo popular (2018a), no qual determinadas formas de feminismo tornam-se mais visíveis do que outras a partir de lógicas (também) mercadológicas. Entretanto, enquanto a ação política fomentada a partir do feminismo popular vai dialogar diretamente com a economia da visibilidade, acionando debates relacionados a questões como empoderamento, confiança, capacidade e competência (idem), os exemplos apresentados apontam para um panorama mais ambíguo, dando a ver a complexidade e os desafios de se pensar a relação entre feminismos, mídia e consumo na contemporaneidade.

\section{Considerações finais}

Neste trabalho, buscamos explorar aspectos relacionados à circulação de discursos feministas no âmbito do YouTube, particularmente nos acionamentos de influenciadoras digitais cuja produção na plataforma é frequentemente permeada por discussões sobre o tema. Ao analisar tais produções à luz de debates caros à teoria feminista, esperamos ter contribuído para explicitar os desafios teóricometodológicos que se impõem diante de fenômenos como a ascensão midiática de novos "nichos" de atuação na disputada economia da atenção on-line.

\section{Dossiê Crise, Feminismo e Comunicação - https://revistaecopos.eco.ufrij.br/}


Tal fenômeno reflete, naturalmente, a própria ampliação dos debates políticos nestes ambientes, que se intensifica à medida que plataformas integram a vida cotidiana, promovendo conversações e formas de mobilização política mais informais (HIGHFIELD, 2016). Por outro lado, à medida que a defesa dos feminismos se torna relevante no agenciamento da visibilidade de influenciadoras digitais, apresentam-se pistas em relação aos atravessamentos complexos que envolvem sua atividade profissional e formas de ativismo. Embora os vídeos analisados possam trazer elementos que remetam à noção de ativismo digital feminista (CLARK, 2016), há que se considerar suas potencialidades e limitações na promoção de transformações sociais efetivas. Além dos vínculos com patrocinadores, explícitos inclusive em vídeos patrocinados vinculados ao feminismo, a visibilidade das youtubers em questão também é mediada por aspectos mercadológicos diversos, influenciados, por exemplo, pelas lógicas de circulação do próprio YouTube.

Contudo, classificar a atuação de Júlia Tolezano, Maíra Medeiros e Nátaly Neri como feminismo popular sem as devidas ressalvas é contribuir para fortalecer dicotomias relacionadas à (falta de) legitimidade de diferentes discursos feministas, justamente o que buscamos evitar. Assim, argumentamos que compreender as articulações envolvidas na emergência midiática de influenciadoras digitais socialmente engajadas aponta para a necessidade de repensar a noção de feminismo popular a partir de nuances mais diversas e complexas. Se oferecem uma versão, sob certos aspectos, espetacularizada do feminismo, não se pode dizer que os vídeos analisados se assemelham sempre a uma sensibilidade pós-feminista, tampouco apresentam o amor próprio ou a autoconfiança como solução única para as desigualdades de gênero que denunciam. 


\section{Referências bibliográficas}

ABERCROMBIE, Nicholas; LONGHURST, Brian J. Audiences: A sociological theory of performance and imagination. Nova York: SAGE Publications Ltd, 1998.

AMARAL, Fernanda Pattaro. 0 fenômeno do feminismo pop do início do século xxi: um movimento de consumo ou estratégia de combate e ruptura? Novos Olhares Sociais, v. 2, n. 2, p. 35-54, 2019.

BANET-WEISER, Sarah. Branding the Post-Feminist Self: Girls' Video Production. In: KEARNEY, Mary (org.). Mediated Girlhoods: New Explorations of Girls' Media Culture. Nova York: Peter Lang, p. 277-294, 2011.

Empowered: Popular feminism and popular misogyny. Londres: Duke University Press, 2018.

152-156, 2018.

Postfeminism and Popular Feminism. Feminist Media Histories, v.4, n. 2, p.

BAUMGARDNER, Jennifer; RICHARDS, Amy. Feminism and femininity: Or how we learned to stop worrying and love the thong. In: HARRIS, Anitta. All about the girl: Culture, power and identity. Londres: Routledge, p. 59-68, 2004.

BURGESS, Jean; FOTH, Marcus; KLAEBE, Helen. Everyday creativity as civic engagement: A cultural citizenship view of new media. In: Proceedings 2006 Communications Policy \& Research Forum: Network Insight Institute, 2006. p. 1-16.

CLARK, Rosemary. "Hope in a hashtag": the discursive activism of\# WhyIStayed. Feminist Media Studies, v. 16, n. 5, p. 788-804, 2016.

DUGGAN, Lisa. The twilight of equality? Neoliberalism, cultural politics, and the attack on democracy. Boston: Beacon Press, 2012.

EVANGELISTA CUNHA, Simone. Lugar de mulher é no YouTube: atravessamentos entre dinâmicas de ativismo, consumo e microcelebridades em plataformas digitais. 2019. $256 \mathrm{f}$. Tese (Doutorado em Comunicação Social). Programa de Pós-Graduação em Comunicação da Universidade Federal Fluminense.

FERREIRA, Carolina Branco de Castro. Feminismos web: linhas de ação e maneiras de atuação no debate feminista contemporâneo. Cadernos Pagu, n. 44, p. 199-228, 2015. FISKE, John. Understanding Popular Culture. Boston: Unwin Hyman, 1989.

FREIRE FILHO, João. Reinvenções da resistência juvenil: os estudos culturais e as micropolíticas do cotidiano. Mauad Editora Ltda, 2007.

FULLER, Sean; DRISCOLL, Catherine. HBO's Girls: gender, generation, and quality television. Continuum, v. 29, n. 2, p. 253-262, 2015.

\section{Dossiê Crise, Feminismo e Comunicação - https://revistaecopos.eco.ufrj.br/}


GILL, Rosalind. Post-postfeminism?: New feminist visibilities in postfeminist times. Feminist Media Studies, v. 16, n. 4, p. 610-630, 2016.

HEYWOOD, Leslie. e DRAKE, Jennifer. Third Wave Agenda: Being Feminist,Doing Feminism. Minneapolis, Minessorta: University of Minnesota Press, 20017.

HIGHFIELD, TIM. 2016. Social Media and Everyday Politics. Cambridge: Polity Press, 2016. HINE, Christine. Ethnography for the internet: Embedded, embodied and everyday. Londres: Bloomsbury Publishing, 2015.

HOOKS, Bell. o feminismo é para todo mundo: políticas arrebatadoras. Rio de Janeiro: Rosa dos Tempos, 2018.

KARHAWI, Issaaf. Influenciadores digitais: conceitos e práticas em discussão. Communicare, v. 17, p. 46-61, 2017.

KELAN, Elisabeth. Performing gender at work. Londres: Springer, 2009.

KELLER, Jessalynn Marie; RYAN, Maureen. Call for Papers: Problematizing Postfeminism. 2014. Disponível em: http://arcyp.ca/archives/4244.Último acesso em 5 abr. 2020.

KELLER, Jessalynn Marie. Virtual feminisms: Girls' blogging communities, feminist activism, and participatory politics. Information, Communication \& Society, v. 15, n. 3, p. 429-447, 2012.

KLAR, Malte; KASSER, Tim. Some benefits of being an activist: Measuring activism and its role in psychological well-being. Political Psychology, v. 30, n. 5, p. 755-777, 2009.

LANA, Lígia Campos de Cerqueira. Heroínas pós-feministas: as contradições da produção audiovisual feminina no YouTube. Revista Estudos Feministas, v. 25, n. 3, p. 1359-1371, 2017.

LISTER, Ruth. Citizenship: Feminist Perspectives. New York, NYU Press, 1997.

LUMBY, Catharine. Past the post in feminist media studies. Feminist Media Studies, v. 11, n. 1, p. 95-100, 2011.

MARWICK, Alice. Postfeminist media culture: Elements of a sensibility. European journal of cultural studies, v. 10, n. 2, p. 147-166, 2017.

Status update: Celebrity, publicity, and branding in the social media age. Connecticut: Yale University Press, 2013.

MCROBBIE, Angela. The aftermath of feminism: Gender, culture and social change. Sage: Londres, 2009.

MÍDIA NINJA. Fênomeno negro no youtube, Nátaly Neri é a nova colunista da Mídia NINJA. Geledés Instituto da Mulher Negra. 2017. Disponível em: <https://bit.ly/2uUH5MV>. Último acesso em: 20 ago. 2020.

\section{Dossiê Crise, Feminismo e Comunicação - https://revistaecopos.eco.ufrij.br/}


NAPLES, Nancy A. Confronting the future, learning from the past: Feminist praxis in the twenty-first century. In: REGER, Jo (org.). Different wavelengths: Studies of the Contemporary Women's Movement. Londres: Routledge, 2014. p. 245-266.

PAPACHARISSI, Zizi. Affective publics: Sentiment, technology, and politics. Oxford: Oxford University Press, 2015.

PARENTES, Júlio.'Tento desfazer tabus', diz Jout Jout, nova sensação do YouTube. 0 Globo. 2015. Disponível em: <https://glo.bo/2YXQAc1>. Último acesso em: 13 ago. 2020.

PAUWELS, Anne. 24 Linguistic Sexism and Feminist Linguistic Activism. The handbook of language and gender, p. 550, 2003.

PIEPMEIER, Alison. Girl Zines: Making Media, Doing Feminism. Nova York: NYU Press, 2009.

REIS, J. Feminismo por hashtags: as potencialidades e riscos tecidos pela rede. In: Anais do Seminário Internacional Fazendo Gênero. Florianópolis. 2017. p. 1-13.

RODROL, Lika e FINCO, Nina. Jout Jout, a youtuber e ex-tímida que virou cronista de uma geração. Revista Época. 2016. Disponível em: <https://glo.bo/20X9riR >. Último acesso em: 13 ago. 2020.

SENFT, Theresa M. Microcelebrity and the branded self. In: HARTLEY, John; BURGESS, Jean; BRUNS, Axel (eds.) A companion to new media dynamics. Nova Jersey: Wiley-Blackwell, p. 346-354, 2013.

SHAW, Frances. The Politics of Blogs: Theories of Discursive Activism Online. Media International Australia, Incorporating Culture \& Policy, s/v. n.142, p. 41-49, 2012.

TAFT, Jessica K. Rebel girls: Youth activism and social change across the Americas. Nova York: NYU Press, 2010.

TUFEKCI, Zeynep; WILSON, Christopher. Social media and the decision to participate in political protest: Observations from Tahrir Square. Journal of communication, v. 62, n. 2, p. 363-379, 2012.

WEBER, Sandra e MITCHELL, Claudia. Imaging, keyboarding, and posting identities: Young people and new media technologies. In: BUCKINGHAM Davd (ed.). Youth, Identity, and Digital Media. Boston: MIT Press, p. 25-48, 2008.

WHELEHAN, Imelda. Remaking feminism: or why is postfeminism so boring?. Nordic Journal of English Studies, v. 9, n. 3, p. 155-172, 2010.

XAVIER, Ana Clara. Maíra Medeiros dona do canal no YouTube 'Nunca te pedi nada' fala sobre feminismo e assédio em papo com o site HT. Heloisa Tolipan. 2017. Disponível em: <https://bit.ly/2KokdQy>. Último acesso em: 18 ago. 2020.

\section{Dossiê Crise, Feminismo e Comunicação - https://revistaecopos.eco.ufrj.br/}

